\title{
PREVALENCE OF RADIOGRAPHIC ABNORMALITIES OF TEMPOROMANDIBULAR JOINTS BY MAGNETIC RESONANCE IN PATIENTS WITH RHEUMATOID ARTHRITIS
}

Ana Maria Tamelini ${ }^{1}$, Maria Bernadete Renoldi de Oliveira Gavi ${ }^{1, \star}$, Livia Guidoni ${ }^{1}$, Ruben Horst Duque ${ }^{1}$, Erica Vieira Serrano ${ }^{1}$, Marcos Rosa Junior ${ }^{1}$, Maria Helena Monteiro de Barros Miotto ${ }^{1}$, Samira Tatiyama Miyamotoํ․ Valeria Valim

1.Universidade Federal do Espírito Santo, Vitória (ES), Brazil.

*Corresponding author: mbernadetegavi@gmail.com

\section{BACKGROUND}

The prevalence of temporomandibular joints (TMJs) arthritis and chronic abnormalities and their association with systemic disease activity and dysfunction are not well studied by magnetic resonance imaging (MRI) in rheumatoid arthritis (RA). The objectives were to describe and quantify MRI findings in TMJs in RA, correlate them with clinical and radiological changes, disease activity and systemic functional limitation in individuals with RA.

\section{METHODS}

Cross-sectional observational study with 50 individuals (100 joints) with RA (ACR/EULAR 2010). They performed MRI of the TMJs to assess the changes recommended by the German scoring system (bone marrow edema, joint effusion, synovitis, erosions and changes in the morphology of the mandibular condyle). Sociodemographic questionnaires, mandibular function impairment questionnaire (MFIQ), health assessment questionnaire (HAQ) and disease activity score 28 (DAS28) were obtained. Sample size and the intraclass correlation coefficient (ICC) were calculated. The ICC assessed intra- and interobserver agreement in the reading of MR images according to the German scoring system. Statistical evaluation included univariate analysis to describe the population profile, the profile of changes in TMJ MRI, bivariate analysis with evaluation of the association between the set of dependent variables and temporomandibular morphoanatomical changes. The chi-squared test $(=0.05)$ and with Bonferroni correction, multivariate analysis using multinomial logistic regression were used.

\section{RESULTS}

The evaluation of MR images showed a high prevalence of findings (acute $84 \%$ and chronic $54 \%$ ) in the TMJs: $84 \%$ synovitis, $82 \%$ synovial fluid, $48 \%$ bone edema, 54\% erosions and 52\% mandibular condylar deformities. There was correlation with indices of mandibular functional assessment (MFIQ) and general functional limitation (HAQ) and disease activity (DAS-28).

\section{CONCLUSION}

The prevalence of acute and chronic abnormalities of TMJs by MRI are high, underdiagnosed and associated with physical dysfunction and systemic disease activity. TMJs should be systematically clinically evaluated to better indicate MRI to assess acute and chronic alterations.

\section{KEYWORDS}

Temporomandibular injury, Diagnosis, Arthritis rheumatoid, Magnetic resonance. 